\title{
LEGISLATING FOR AIR QUALITY MANAGEMENT: REDUCING THEORY TO PRACTICE
}

\author{
George HageviK*
}

\section{INTRODUCTION}

Air pollution is more or less representative of the nation's increasing environmental problems in that while it has been with us for some time it has only recently grown to a scale where differences in degree have begun to become differences in kind. Up to some level of concentration, disposal of wastes is for the most part a local irritation. But, at a certain threshold, costs to society start to increase significantly. This phenomenon has resulted in a considerable redefinition of air pollution problems. For example, the concern is no longer so much with smoke damage as with harm from photochemical smog and other synergistic effects. Also, a higher aspiration level on the part of the population of metropolitan areas has resulted in a reduced tolerance for anything impairing the quality of the environment. These and other changes in the nature of the air pollution problem suggest a new or at least a broader view of planning for air quality management.

The regulatory machinery for dealing with the air pollution problem is still for the most part of a primitive variety. The Air Quality Act of Ig67 assigns primary responsibility for devising the regulatory mechanism to state governments, subject to review by the Department of Health, Education, and Welfare (HEW), and appears to contemplate that new legislation or regulatory action will appear at the state and local level as soon as HEW provides the data and criteria for which it is responsible under the act. ${ }^{2}$ The resultant need for review of laws and standards, coupled with changing perceptions of the problem, suggest that a new generation of legislative responses at the state and local level is to be both hoped and looked for. In the formulation of this new response, greater sophistication will be needed if the considerable costs involved in air pollution abatement are to be minimized, and it is not clear that existing air quality management efforts are yielding the experience necessary to guide the legislatures in this direction. Perhaps greater assistance will come from economists and other experts who can recognize that the legal attack on air pollution requires a new strategy, not just further adaptations of old approaches originally designed to deal with zoning and nuisances.

- B.A. I960, M.A. I963, University of Washington; M.R.P. 1966, University of North Carolina; Ph.D. candidate, University of North Carolina. Assistant Professor of City and Regional Planning, Rutgers University (effective January 1969 ).

The author gratefully acknowledges the assistance of the editor in the preparation of portions of this article.

${ }^{3} 5 \operatorname{ror}(a)(3), 8$ I Stat. 485.

ग5 Ior(b), 106, 107, 81 Stat. 485. 
This paper first attempts to set down some basic social science theory about the economics of air pollution and about decision making in general. It then seeks to apply this understanding in the development of a hypothetical regulatory program for dealing with stationary sources of pollution. This hypothetical program owes little to existing control efforts and is conceived in the understanding that regulatory officials must be enabled to operate effectively even in the dim light of partial knowledge defining and relating the social and technological aspects of air pollution. Since the program is merely sketched, it will not serve as a blueprint but only as a stimulus to new thinking about air quality management and the organization for carrying it out.

\section{I}

\section{The Economist's View-Effluent Fees}

Readings in welfare economics published during the last thirty years are replete with references to smoke damage as a classic instance of what are called negative externalities. ${ }^{3}$ Such discussions, however, have been of more value to economists interested in the further theoretical development of welfare economics than to the air pollution control officer concerned with actual abatement and control activities. Unfortunately, in this instance the spillover from theory to practice has been minimal. Why is this the case? For one thing, the economic theory requires limiting conditions and large assumptions about the data available, neither of which can be fulfilled in practice. The problems of collecting data on such subjects as air pollution damage and the contribution of each emitter to existing concentrations are staggering, to say the least, and economists have not had the fortitude or the means to tackle the measurements necessary to make concrete control proposals. Sheer complexity has discouraged interest, and, until very recently, there was apparently less investment by government and private funding agencies in this field of economic research than the need seems in retrospect to have warranted. In any event, the theory has proved not too difficult to master, but attention is only beginning to focus on the need for data and practical means of developing these data or compensating for the lack thereof. The 1966 volume, The Economics of Air Pollution, edited by Professor Harold Wolozin, is probably the best single indicator both of economists' increased interest in the problem and of the gulf remaining between theory and practice.

The practitioner looking for practical answers in the Wolozin volume will be disappointed for it is little more than a summary-albeit an excellent one-of the 'state of the art. The primary contribution of the book is that it brings relevant economic theory to bear on the problem, explicitly or implicitly reveals the advan.tages and weaknesses of the economist's approach, and suggests data deficiencies and research needs. The consensus of the participants in the forum from which the

\footnotetext{
${ }^{3}$ E.g., A. Pigou, The Economics of Welfare 160-6I (1932).
} 
book was drawn seems to be that the problem has been defined and that the task: for the next few years is to gather data and do research that might lead to estimates of the necessary answers. If an analogy to water quality management holds, the estimate of a few years seems optimistic. For, even though economists have been concerned with water resource development for some time, Allen Kneese's seminal work on water quality, The Economics of Regional Water Quality Management, did not appear until rg64.

The economist's views on air quality management can be usefully reviewed in a brief manner. Most economists would state the problem in this way: The discharge of pollutants into the air imposes on some people costs which are not adequately borne by the sources of the pollution due to the failure of the market mechanism, resulting in more air pollution than would be desirable from the point of view of society as a whole. The "classical" economic theorist's distinctive approach to the problem is manifested in his belief that the objective of pollution abatement programs should be to minimize the total of ( $a$ ) air pollution damage costs and (b) the costs incurred in any program to alleviate that damage. Any given level of pollution abatement should be reached by the least costly combination of means available, and the costs of any decrement of pollution should not exceed the benefits obtained by the reduction. Thus, the standard theoretical approach would be to calculate the damage to each receptor from polluted air containing various amounts and kinds of effluents. Such a calculation would permit measurement of the benefits to be expected from proposed abatement projects. Next, one would calculate the cost to each pollutant source of abating its emissions in varying degrees. The optimal allocation of the air resource would then require that pollutants be prevented from entering the atmosphere at levels which would inflict more marginal damage on receptors than the marginal cost to the source of preventing the pollution. ${ }^{4}$

The operational procedure which economists would recommend for achieving this optimal condition would include an evaluation of the damage done by the emission of incremental amounts of pollutant into the air at any given location and time and an assessment of a corresponding charge against the emitters. The charge would thus reflect the marginal costs that the sources impose on others. It would be determined by relating ambient air quality to rates of emission, using air monitoring networks and relatively simple atmospheric diffusion models.

The principal advantage from the economist's point of view of "internalizing" the cost by means of a government-levied charge on the source is that the economic units involved can decide on the best adjustment to be made in light of the costs

\footnotetext{
'A detailed statement of this approach is found in Crocker, The Structuring of Atmospheric Pollution Control Systems, in THE Economics of AIR PoLLUTION (H. Wolozin ed. 1966) [hereinafter cited as WoLozin]. For a refinement of the problem of determining which abatement expenditures are justifiable, see notes $69-70$ infra and accompanying text.
} 
and benefits they perceive. Those firms which can reduce emissions at a cost that would be less than the charge will do so to avoid being assessed the charge. Those firms which cannot reduce emissions at a cost that would be less than the charge would elect to pay the fee but would nevertheless have a continuing incentive to reduce emisssions. Thus, the optimal level of pollution abatement will be approached by the method that is least costly to society as a whole.

Under this system, management rather than government officials would bear much of the burden of investigation and decision making, and management is said to be better able to evaluate the advantages and disadvantages of the various ways of dealing with the effluent problem and to choose the best mix. This is held to be preferable to being restricted to any one abatement technique. Implicit in the economist's view is recognition that the optimal level of air pollution abatement is closely tied to the technological processes involved, with the least-cost solution being in many cases a complex combination of process changes and treatment of effluent; in some cases, moreover, the least-cost solution might involve partial abatement and payment of the lower effluent fees associated with the remaining emissions. The continuing incentive provided by the effluent fee to search for additional or alternative ways of abating discharges involves a much different response than that compelled in a straight enforcement action. Enforcement by criminal proceeding or by injunction or cease and desist order, for example, would provide no real alternative to incurring the abatement costs, whatever they might be. Moreover, enforcement programs that would compel the adoption of specific technology would altogether destroy the incentive to explore alternative abatement techniques or to combine approaches to achieve the maximum efficiency in pollution reduction.

A system of effluent fees has additional theoretical appeal because of its adaptability to changing or variable circumstances. Fees can be varied up or down in accordance with weather conditions, the time of day, the season of the year, and other factors in order to correlate emitters' costs even more closely with the damage caused. The theoretical advantage of this flexibility may be difficult to realize in practice, however, and indeed may even prove a liability. Given the vast inadequacy of data and the probabilistic character of the factors that might be reflected in variable fees, the schedule would take on an appearance of arbitrariness that might be difficult to dispel. We have here one key to the unlikelihood that effluent fees will soon play a major role in air quality control.

The primary problems with effluent fees are simply the shortage of data and the lack of agreement on many of the theoretical problems that are presented. The major information deficiency is in the measurement of damages attributable to particular pollutants, and myriad conceptual and informational problems inhere in the allocation to individual polluters of the share of the total damages for which they are "responsible." Perhaps most difficult of all is the theoretical problem of allocating damages to specific polluters when synergistic effects occur-that is, where the 
combination of two or more pollutants, such as sulfur oxides and particulates, causes greater damage than either pollutant could cause alone. Problems of equity are also presented by the need to allocate damage costs between new and existing industries. Finally, there are also doubts that monitoring technology is adequate to permit effective enforcement of an effluent fee system. Especially where there are numerous small polluters to be monitored, such a system would be costly to administer.

Another problem, which must be faced in any regulatory system, with or without effluent fees, has to do with the determination of who should benefit from the use of the air resource. If air is to be treated as a free good for the receptors, including humans, plants, and animals, certain costs are thus imposed on others who may wish to use the air for waste disposal. Theoretical discussions seldom deal with why these costs should not be allocated according to "practical" considerations such as the supposed ability of industry to pass on added costs to consumers and the apparently greater ability of industrial firms to select and apply the least-cost solution (including the possibility of paying adjoining landowners to move or take protective measures). An effluent fee program might be designed to encourage such flexibility, but administrative problems would again seem to be overwhelming in the short run.

While these many problems and data shortages will handicap any program of enforced abatement which purports to compare abatement costs and the benefits derived therefrom, an effluent fee program would also have to survive legal attacks based on arguments of apparent discrimination and abuse of the taxing power. As understanding of the nature of air pollution and pollution damage costs increases, effluent fees may become more feasible and may ultimately fill an important role in air pollution control. But today, while the assignment or sale of emission or receptor rights has theoretical appeal, the pricing of such rights still requires some sort of centralized decision-making system. Such a system, as it might now be constituted in our political and institutional environment, would yield only a few of the advantages that a fully market-oriented system, from which it is conceptually derived, would produce.

Finally, a basic complaint against the theoretical underpinnings of the effluent fee approach has been raised by Wolozin, who states,

My skepticism is based on the unfortunate fact that we do not know enough in an empirical way about the effects of taxation on business policies and human behavior to be at all certain about the outcome of any scheme of tax like effluent fees. Even the underlying theory can be questioned. ${ }^{5}$

This questioned theory is, of course, the conventional neoclassical microeconomic model, which depends upon the postulate of rationality and the concept of the firm as a profit maximizer. Since these assumptions have often been criticized as un-

\footnotetext{
"Wolozin, Discussion, in Proceedings: The Thro Natronal Conference on Am Pollution 580 (Public Health Service Pub. No. I649, I967) [hereinafter cited as Thrrd Nat's Conf. Proceedings].
} 
realistic, Wolozin suggests that a more useful approach might be to view the goals of the firm in relation to its position as an organization in a political and social system. ${ }^{6}$ Wolozin's point is not well taken, however, for it seemingly ignores threc fundamental considerations. First, many significant polluters will in fact be entrepreneurs in the traditional sense rather than firms in which management has become independent of ownership, the condition usually cited as having undermined the profit-maximization postulate. Second, the proposition that management generally prefers lower costs to higher is a principle which has never been directly criticized, and it holds largely true even in regulated public utilities where "regulatory lag" permits realization of profits wherever unanticipated cost savings can be accomplished. ${ }^{7}$ Finally, Wolozin misses the notable fact that management's presumed social responsibilities, which are so strongly emphasized by those who would contest the profit-maximization postulate, are also at work in this field, assisting in the achievement of the social goal of a cleaner environment. One might predict, therefore, that effluent fees, by raising the cost of not fulfilling a perceived social responsibility to abate, will yield dividends greater than traditional theory would anticipate.

In sum, effluent fees have a solid theoretical foundation, but the practical problems associated with establishing and enforcing a fee schedule appear so great that immediate adoption of this approach seems unlikely. Understanding of the air pollution problem and the regulatory challenge it poses nevertheless requires a grasp of effluent fees' potentiality, since a system of fees may be the ultimate goal toward which regulation should evolve. Vickrey's advocacy of an effluent fee program rests in part on the consideration that it would force the regulator "to bring the problem into perspective, and tends to put something of a restraint on the pure air enthusiast who might at times be inclined to impose standards that would entail too high a cost relative to benefits." ${ }^{8}$ One premise of the hypothetical regulatory program developed below is that the cost-benefit principle can also be implemented in a program of direct regulation and that the lesson Vickrey wants taught can be learned without opting for effluent fees as the dominant regulatory approach.

\section{II}

\section{Choice of a Control Philosophy}

\section{A. Alternative Approaches to Control}

In addition to the effuent fee approach, payments and direct regulation are other approaches to environmental quality management problems. ${ }^{0}$ Direct regulation is

${ }^{\circ} I d$.

${ }^{7}$ But cf. comments by Linsky, Mills, and Wolozin, id. at 589 .

${ }^{8}$ W. Vickrey, Theoretical and Practical Possibilities and Limitations of a Market Mechanism Approach to Air Pollution, a paper presented at the Air Pollution Control Ass'n Conference, Cleveland, Ohio, June I967.

See generally A. Kneese, The Economics of Regional Water Quality Management 193-95 (1964); Mills, Economic Incentives to Air Pollution Control, in WoLoziN 40. 
somewhat different from the other two in that it is nonfiscal. The payments approach includes not only subsidies but also reductions in taxes that otherwise would be collected. Common examples include the subsidization of particular control equipment, accelerated depreciation, and tax credits for investment in control equipment. Direct regulation includes a mixed bag of licenses, permits, registration, zoning, air quality and effluent standards, and the enforcement of standards through regulatory bodies and the courts.

\section{Payments}

One possible payment system might rely on selective payments to waste contributors for the purpose of motivating them to restrict emissions to an optimal degree. These payments would in principle be equivalent to the off-site costs imposed by increments of waste discharge and would vary with atmospheric conditions and effluent location, as well as with the quantity and quality of effluent. Since this sort of payment would be similar in theory but opposite in approach to the effluent fee scheme, the criticisms and difficulties mentioned above would apply here also.

The more typical proposal under the payments heading, however, relates to tax relief or subsidies. Such proposals are a popular topic these days, particularly among industry representatives and members of Congress, but they have only one substantial argument in their favor-there is less resistance to a program of subsidies than to programs of regulation. There are, however, a number of problems with the payments approach. As Mills states,

[T] here is a strong practical argument against most of the policies under the payments heading. They are simply payments for the wrong thing. The investment credit proposal will illustrate the deficiency that is common to others. An investment credit on air pollution abatement equipment reduces the cost of such equipment. But most such equipment is inherently unprofitable in that it adds nothing to revenues and does not reduce costs. To reduce the cost of such an item cannot possibly induce a firm to install it. The most it can do is to reduce the resistance to public pressure for installation. Common sense and scattered bits of evidence suggest that these payments policies are costly and inefficient ways to achieve abatement. ${ }^{10}$

More specifically, it would be difficult to decide how much to pay to whom for any level of pollution abatement since there is no commonly accepted level of air quality from which payments could be computed. The taxpayer's feelings of equity might also be violated since the industrial firm, in not having to consider pollution abatement as a cost of production in the same sense that labor and capital are, would rely on payments raised at least partially by higher taxes on other taxpayers. $^{11}$

Payment schemes, tax credits, or accelerated depreciation may also bias the tech-

\footnotetext{
${ }^{10}$ Mills, Federal Incentives to Air Pollution Control, in Throd Nar'l Conf. Proceedings 575-76.

11 See Mills, supra note 9, at 45-46.
} 
nique used for control in an uneconomical direction because they tend to promote construction of treatment facilities when adjustments in production processes, products, or inputs might achieve the same result at lower cost and might even increase productivity. Tax writeoffs of capital cost are also at a disadvantage because they are not capable of reducing all abatement costs. It has been estimated that capital cost accounts for only about one-eighth of the air pollution abatement costs for a typical firm. ${ }^{12}$ Indeed, fuel substitution alone is estimated to be the least-cost alternative in over sixty per cent of the cases involved in air pollution abatement. ${ }^{13}$

Grants and loans have the same objectives as tax writeoffs in that they lower the cost of capital expenditures. Thus the criticisms suggested above apply. However, it has been suggested that if grants were made for both capital and operating costs and administered through regional air quality management organizations this particular criticism would lose much of its bite. But it must be remembered that extensive reliance on grants and loans suffers from the uncertainty of fluctuations in legislative appropriations.

\section{Direct Regulation}

Although the ideal method for dealing with the effects of the unidirectional external diseconomies associated with air pollution would be a system of effluent charges, it is often suggested that the best operational method for dealing with practical problems is direct regulation. Existing federal policies on air pollution abatement mostly fall in the category of regulation and enforcement activities. ${ }^{14}$ The advantage of this approach is that it permits the government to take interim steps even though it has almost no idea of relevant measurements. For example, if people's eyes were burning because of obvious emissions from an industrial plant, it would be logical to require filtration of these emissions even if one had no way of measuring the amounts of the emissions. Such regulation can be justified since, as a report of the staff of the Senate Committee on Public Works states, "Whatever yardsticks are employed, it is clearly evident that the cost of property damages alone from air pollution is great-far greater than the amounts devoted to its abatement by industry and all levels of government."15 The implication seems to be that there is little chance of the costs of such a program exceeding the benefits.

Not all economists view direct regulation with complete suspicion. Crocker states,

\footnotetext{
${ }^{12}$ Working Comm. on Economic Incentives, Federal Coordinating Comm. on the Economic Impact of Pollution Aantement, Cost Sharing with Industry? 27 (Summary Report 1967) [hereinafter cited as Federal Coordinating Comm.]

${ }^{18}$ Id.

${ }^{16}$ For a full discussion of federal powers under the statute, see Martin \& Symington, $A$ Guide to the Air Quality Act of 1967 , in this symposium, p. 239.

${ }^{15}$ Staff of the Senate Comm. on Public Works, 88tri Cong,, ist Sess, A Study or PollutionAIR 20 (Comm. Print r963).
} 
Given the uncertain quality of available physical, biological, and economic information, and the potentially high costs associated with the gathering of additional information about atmospheric pollution problems, the control authority, in order to impress receptors and emitters with the necessity of regarding the air's two value dimensions as scarce economic resources, appears to be justified in setting minimal standards. ${ }^{18}$

A greater commitment to standards is evident in the writings of Paul Gerhardt, an economist with the National Center for Air Pollution Control. He states,

A polluter faced with the necessity to comply with a law or suffer punishment will generally find the least cost set of controls or have no one to blame but himself. He will pass cost increases along to customers in the form of price increases or to equity holders in the form of reduced profit shares. Optimum allocation will be preserved as the public makes new choices about their spending and investing patterns. Administrative costs could be less than for some alternatives as there would be no complicated tax revenue emission charge or payment system to operate. ${ }^{17}$

But, as expected, relative simplicity is not achieved without certain costs. One objection to direct regulation is its allegedly extreme inflexibility which results in considerably higher costs than would more selective abatement. To use an example from water pollution, the Federal Water Pollution Control Administration found in the Delaware River Basin that simple equal-proportional reduction of all waste loads would cost fifty per cent more than achieving the same quality standard by requiring firms to reduce their waste loads in proportion to their harmful effects. ${ }^{18}$ In the case of air quality management, the Federal Coordinating Committee on the Economic Impact of Pollution Abatement suggests that the cost of achieving a specific air quality standard could increase by 200 to 400 per cent if equalproportional reduction on a year-round basis were attempted. ${ }^{19}$

The argument over the desirability of direct regulation cannot be resolved on the merits here. It is perhaps more important, however, to note that government already appears to be committed to direct regulation as the preferred means of dealing with the air pollution problem, although subsidies and tax concessions will continue to appear. While Congress did not see fit in the Air Quality Act to enact the President's proposal for a program of national emission standards for all polluting industries, such standards are still under consideration. ${ }^{20}$ Moreover, most state and local abatement programs are based on strict prohibitions of the emission of specified concentrations of pollutants. Against this background, the final section of this article, in developing a hypothetical program of direct regulation, is premised on

\footnotetext{
${ }^{10}$ Crocker, smpra note 4 , at 79.

${ }^{17}$ P. Gerhardt, Some Economic Aspects of Air Pollution, a paper presented at the Mid-Atlantic States Section, Air Pollution Control Ass'n Conference, Oct. 4, 1967.

${ }^{18}$ Federal Coordinating Comm. I4.

${ }^{10} \mathrm{Id}$.

${ }^{20}$ See Air Quality Act of $1967, \$ 21$ I (a), 8x Stat. 485.
} 
these judgments, among others: (I) that government has already opted for a direct regulation approach, (2) that such an approach holds fewer dangers of resource misallocation and inequity than would a payments or subsidy program, (3) that direct regulation would be more likely to operate effectively with necessarily imperfect data than would an effluent fee approach, and (4) that its legal status might be somewhat less open to question than an effluent fee program simply because it is somewhat less of a novelty in the spectrum of public policies. Finally, while it is believed that there is already a commitment to regulation, the shape of the regulatory machinery, the details of the policies to be implemented, and the decision-making methodology to be employed do not seem to be finally determined. The hypothetical program is thus framed to encourage maximum flexibility in pursuit of least-cost solutions, which economic theory tells us are important and can help us to find.

\section{B. A Larger View of Decision Making}

To this point the review has been over what should be familiar ground. Unfortunately for many practitioners in the field of air quality management, knowledge relating to benefit-cost ratios, marginal cost pricing, and optimal taxing schemes has been secondary to the necessary concern with temperature inversions, wet scrubbers, filters, and the like. This is the case even though air pollution is in a fundamental sense a social and economic problem the solutions to which have to be worked out within a complex political and institutional framework. Technological means are currently available to purify the air to any desired degree, but costs increase significantly as more control is desired. ${ }^{21}$ The economist's view of air quality management is important because we are finally perceiving a condition of scarcity so central to his thinking. Air is now viewed as a congested facility, and without the attempt at evaluation he provides, the desirable objective of reducing the level of pollution in the atmosphere by the least costly means possible would be difficult to achieve.

Since pollution abatement is primarily a matter of avoiding costs, programs need to be initially evaluated from an economic point of view for, as Turvey has noted, "even though an economic calculation of gains or losses is often not sufficient to reach a well based decision, it is nearly always an essential preliminary."22 This determination of sound economic policy in air quality management requires an accurate and continuing evaluation of the costs of abatement relative to air pollution damages. Viewing costs avoided as benefits, decisions need to be sought that maximize the present value of net benefits. ${ }^{23}$ Ideally, this analysis would be

\footnotetext{
${ }^{21}$ The main technological problem that remains to be solved is the development of a method of monitoring levels of emission accurately and at low cost.

${ }^{22}$ Turvey, Side Effects of Resource Use, in Environmental Quality in a Growino Economy 52 (R. Jarrett ed. 1966 ).

${ }^{23}$ This is essentially a benefit-cost view of air quality management since one may alternatively refer to (I) damages (costs) avoided as benefits and (2) costs incurred for abatement as costs, and say that
} 
directed toward finding abatement efforts that equate incremental abatement costs and the value of incremental damage costs reduced. ${ }^{24}$ But even a less sophisticated approach could measure abatement costs so that they include both administrative costs of control and capital and process change costs associated with abatement. Tools of evaluation, whether in sophisticated or crude form, need to be applied not only to the theoretical ideal of effluent fees and charges but also to the actual or potential use of payments and continuous and noncontinuous emission standards under a program of direct regulation.

While direct regulation seems to be emerging as the dominant control philosophy, the regulation to be undertaken may nevertheless comprise subsidies, licenses, permits, effluent charges, emission standards and variances therefrom, emergency powers, and some reliance on market forces. Experimentation with regulatory approaches to determine the best mix of such control techniques is desirable, and this need should be recognized by HEW in its review of state enforcement plans under the Air Quality Act. Such experimentation can be accomplished most readily by a control agency that is given broad powers with discretion to choose the tools needed for particular purposes. The hypothetical regulatory program described below contemplates such experimentation.

The overriding decision-making issue in this field is simply the difficulty of regulating an activity requiring prompt and decisive regulatory attention under conditions of imperfect knowledge, information, and understanding. The need for experimentation stems from these uncertainties. Ridker, commenting favorably on the need to get on with the job of regulating and the desirability of regulatory experimentation, quotes a British air pollution control official as follows:

You Americans behave as if you have sufficient time and money to investigate a problem to death before you decide to act. In Britain we take note of a problem we do not like, take some action to correct the problem, and then do research after the fact to determine whether we were right. ${ }^{25}$

Such a purely seat-of-the-pants approach might not be politically feasible in this country and might be open to legal attack. Nevertheless, regulation must proceed with only partial knowledge, and if sensible and progressive regulation is to be achieved, substantial decision-making powers must be delegated to control agencies along with the discretion to experiment and innovate control approaches. The challenge becomes one of devising an effective decision-making process, with the

waste reduction up to but not beyond a certain point will maximize benefits minus costs. Cost minimization (including damages as a cost) and net benefit maximization are in this case identical.

"It is significant, as Gerhardt points out, that there has been far more interest in assessing the value of the damage by air pollution than in the costs of control. The costs of recent attempts at contro] have generally been accepted as a fraction of total damages. The interest in incremental costs of control will increase as the point of equality between incremental control costs and incremental damages is approached. See Gerhardt, supra note 77 . For an argument suggesting that abatement costs should be a matter of immediate concern, see notes 69-70 infra and accompanying text.

${ }^{28}$ Ridker, Strategies for Measuring the Cost of Air Pollution, in Wolozin 87, 100. 
decision maker's discretion structured and guided by legal principles, growing technical understanding, and clearly defined legislative goals, and with opportunities for participation by affected parties in the decision-making process. Social science theory can again be turned to, this time for guidance in the shaping of such a regulatory program.

\section{III}

\section{The Role of Bargaining}

Social scientists have developed a plethora of overlapping and competing theories and models of the decision process. The literature on the subject is vast, and any attempt at synthesis here would only result in confusion for the reader ${ }^{20}$ What is needed at this stage is a theoretical framework that relates social, political, and economic behavior to the institutional structures under consideration in a program of air quality management. Such a framework, concerned with the actors in the decision process, the strategies they pursue, the nature of the information available to all parties, and the environment in which decisions are made, would be of great assistance to legislators attempting to develop more rational regulatory institutions for securing pollution abatement. The following discussion may help to provide a conceptual approach to the formulation of an effectively functioning control program.

\section{A. Theory of Conflict Resolution}

Significant public policies originate in the conflict of group interests. ${ }^{27}$ The peaceful resolution of these conflicts is generally achieved through reconciliation, compromise, or an award process in which both parties agree to accept the verdict of an outside person or agency. ${ }^{28}$ Reconciliation relies on discussion to lessen the differences of opinion between the participants. Compromise uses the mediation and conciliation aspects of bargaining, while an award is achieved through arbitration or legal trial. In air quality management or in any other environmental management program none of the three types of resolution can be considered as an independent technique for pollution abatement, although one form might predominate. Indeed, Boulding asserts that reconciliation and compromise might occur simultaneously, that some reconciliation may be necessary before compromise is possible, that there are likely to be elements of discussion and propaganda in bargaining situations, that in arbitration cases or in court proceedings there are often elements of bargaining and reconciliation before the award is announced, and that an

\footnotetext{
${ }^{26}$ For a useful review of the major contributions in the area of decision theory, see Robinson a Majak, The Theory of Decision-Making, in Contemporany Potmtrcal Analysis 175 (J. Charlesworth ed I967).

${ }^{27}$ See, e.g., J. Anderson, Politics and the Economy (1966).

${ }^{98}$ See T. Schelling, The Strategy of Conflict 3-20 (xg66).
} 
award might not be accepted unless it has been preceded by informal reconciliation and bargaining. ${ }^{29}$

Game theory has become one principal avenue for research on conflict resolution, and it is usually defined as the formal study of rational decisions in situations where "two or more individuals have choices to make, preferences regarding the outcomes, and some knowledge of the choices available to each other and of each other's preferences."30 It is concerned with situations-games of strategy-in which the best course of action for each participant depends on what he expects the other participants to do, with the outcome a function of what choices are made by the other actors. The individual decision units have only partial control over the strategic factors affecting their environment, since the essence of the game is that it involves adversaries whose fates are intertwined. In a sense each group or individual faces a cross-optimization problem in which plans must be adjusted not only to one's own desires and abilities but also to those of others.

Bargaining, which is defined as the process by which a tolerable settlement for all participants is reached, ${ }^{31}$ falls within the theory of games but is a species of game in which relatively little progress has been made, partly because it includes situations involving common interest as well as conflict between opponents. ${ }^{32}$ Cooperation is useful in this type of game because within some range of possibilities both parties will be better off with a solution, i.e., bargain, than without one. Conflict is involved because within this range of solutions the participants compete for the most favorable distribution of benefits. Thus, while both parties are interested in the adoption of some solution, they have divergent interests with regard to the particular solution that is adopted. ${ }^{33}$

Although bargaining has been widely studied and discussed, it is not always clear, as McKean has pointed out, ${ }^{34}$ just how bargaining works. Because of this lack of knowledge, bargaining is often viewed as a constraint in decision making rather than as a variable that could be manipulated to achieve a least-cost solution. ${ }^{35}$ The

\footnotetext{
${ }^{29}$ K. Boulding, Conflict and Defense: A General Theory 310-13 (I962).

${ }^{80}$ Schelling, What is Game Theory?, in Contemporary Political Analysis 213 (J. Charlesworth ed. 1967).

${ }^{21}$ See Banfield, Notes on a Conceptual Scheme, in Politics, Planning and the Public Interest 307 (M. Meyerson \& E. Banfield ed. 1953).

${ }^{82}$ In the terminology of game theory, bargaining is a positive-sum (as opposed to zero-sum), frequently nonsymmetrical game between participants with a mixture of conflict and cooperation. Zero-sum games are those in which one player's loss is the other's gain. The sum of gain plus loss is zero-hence "zero-sum." A positive-sum game is one in which the gain of one party is not equal to the loss of the other. For example, a gain for $A$ of one unit of value may only cause a loss to B of one-half unit. A nonsymmetrical game results when B's loss varies from move to move even though A's gain with each move is constant. These variations from the zero-sum prototype make the mathematics of a game extremely complex.

sa This dichotomy gives the bargaining game its unusual character and raises issues quite different from pure conflict or pure cooperation games.

86 MeKean, The Unseen Hand in Government, 55 AM. Econ. Rev. 494 (1965).

${ }^{86}$ See R. Cyert \& J. March, A Behuvioral Theory of the Firm 3 I (I967).
} 
usual explanation for this situation is that there are no generally accepted operational criteria for determining economic efficiency, that there are many competing groups with diverse interests and values seeking to influence policy making, and that a variety of political, social, and ethical as well as economic considerations are involved in the making of public economic policy. The policy process involves the striking of balances and the making of compromises more often than the finding of "correct" policies or the choice between "right" and "wrong" in any absolute sense. Given the suggested importance of bargaining in the decision-making process, bargaining should no longer be viewed as a constraint within which one attempts to optimize. There are obvious costs and benefits associated with shifts in bargaining behavior that can be identified. Current and anticipated research on decision making in air quality management needs to take cognizance of the role of bargaining, and the researcher should seek to identify the costs and benefits attached to any bargaining solution.

While economists and mathematicians have developed highly sophisticated approaches to game theoretic decision making, such methodology might be only tangentially relevant to decision making in air quality management. For the social scientist that which is conceptual and rudimentary in game theory is the most valuable. $^{36}$ Rather than being thought of as a formal "theory," it is now viewed as a framework for analysis which can be adapted and modified according to specific needs. In essence, it provides a point of reference for examining a problem and gaining needed insights without accepting the often unrealistic rules of the game. With this in mind, the following section reviews some of the insights gained in the study of the bargaining aspects of game theory that might have potential application in devising a regulatory framework for air quality management. Because it is within the legislative power to change the rules and context within a particular "game" situation, understanding of the forces at work would assist in making institutional and substantive adjustments that will contribute to more nearly optimal outcomes.

\section{B. Some Insights from Bargaining Theory}

\section{Continuous Games}

Research on conflict situations clearly shows that negotiation and bargaining operate best in situations where the subject in contention can be divided into parts that can be dealt with sequentially. This incrementalism, whether achieved by changes in moves or in value systems, is of considerable importance. ${ }^{37}$ To draw the analogy of chess, players move in turn, each moving a piece at a time; the game proceeds at a slow tempo by small increments and is of an indeterminate length. The game changes character in the course of play by a succession of small changes

\footnotetext{
${ }^{80}$ See, e.g., Schelling, supra note 30, at 219; Shubik, The Uses of Game Theory, in ConTEMporary Political Analysis 260 (J. Charlesworth ed. 1967).

${ }^{\mathrm{aT}}$ See T. Schelling, supra note 28 , at 170.
} 
that can be observed and appreciated, with plenty of time for mistakes of individual players or mutual mistakes which can be noticed and adapted to in later play. In an uncertain situation, a person is often saved from making a strategic error if he hesitates, so the capacity to make future decisions is not relinquished. ${ }^{\mathbf{3}}$

The decomposition tactic in bargaining can be applied to either threats or to promises, and can be viewed as a necessary prerequisite for making a bargain enforceable. This is so since there is a perception on the part of the participants that future possibilities for agreement will not develop unless mutual trust is created and maintained. The participants need to be confident that each of them will not jeopardize opportunities for future agreement by destroying trust near the start of the game. ${ }^{39}$ Such confidence is naturally not always in evidence, so decomposition serves to encourage the same expectations on the part of all participants. An aspect of building mutual expectations is that if a threat can be decomposed into a series of consecutive threats, there is an opportunity to demonstrate to an opponent during his initial reaction to a threat that you "mean business," thereby making the continuous game a learning experience. ${ }^{40}$ Although it is possible that future opportunities for bargaining are not anticipated, a semblance of a continuing game can be created by separating the issue at stake into consecutive components. The principle is also apparent that it is poor strategy to require compliance in terms of some critical amount or degree that would be deemed mandatory, for action geared to increments has a greater chance of success than one that has to be carried out either all at once or not at all once some particular point has been reached.

This is a concern of some importance in environmental management situations since they are structurally "lumpier" than chess games. There is no continuous range of choices open to the polluter and the abatement officer. Due to the initial administrative and psychic costs and the initial and marginal capital costs, moves have a considerable impact, and it is usually difficult to project a control situation more than a move or two ahead. The pace of the game can bring things to a head before much experience has been gained or much of an understanding reached unless ways are found to increase the number of possible moves. The use of incrementalism in structuring pollution abatement progress eases the impact of each move and allows the participants to acquire both knowledge of each other and experience with the particular problem at hand. Costs are spread over a longer period of time, and the slower pace of the process and the indeterminate length of the "game" reduce the possibility of crisis. Because of these advantages gained through the use of incrementalism, one would expect that conscious attempts would be made to increase the number of "moves" and extend the life of the game. It is of interest that the Air Quality Act specifies that multiple actions must take place before final regulatory

\footnotetext{
${ }^{38}$ See K. Boulding, The Impact of the Social Sciences 43 (1966).

${ }^{80}$ See T. Schelling, supra note 28 , at 45 .

${ }^{\circ 0}$ This learning process is detailed in A. Rappaport \& A. Ghammar, Prisoner's Dilemma (I965).
} 
action occurs. ${ }^{41}$ These steps make the process more incremental in nature, thus gaining for the participants the advantages described above.

Another aspect of the continuous game which must be considered is that negotiating processes develop certain rituals, and attempts to bypass or reduce these rituals may destroy the negotiating process itself. ${ }^{42}$ For example, the parties begin the proceedings with somewhat bombastic statements that set the initial boundaries to the negotiations. There is a period of withdrawal designed to make it appear that the commitments are genuine. The parties know, however, that the commitments are not absolute; otherwise the negotiations would break down. There may follow a process of trading by which mutual concessions are made, and there may have to be a period during which, even though no visible progress occurs, the incipient settlement is in fact developing. The resolution of conflict through bargaining thus involves the difficult institutional problem of arranging these ritual elements in the proper order and proportion. ${ }^{43}$ Because legal procedures may be too inflexible to permit the proper mix of ritual elements required by the bargaining and reconciling processes, a formal legal proceeding may often be a poor way of handling a conflict in air pollution control.

\section{Focal Point Solutions}

In bargains that involve quantification of solutions, such as the setting of emission and ambient air standards, there seems to be some appeal in mathematical simplicity. Outcomes tend to be expressed in even numbers since they provide good "resting places." ${ }^{\text {"4 }}$ Thus a compromise at forty-seven per cent is much less likely than at fifty per cent. Just as the mathematical properties of a game can influence its outcome, the perception by the participants of the historical, cultural, legal, and moral properties of the game can serve to focus expectations on certain solutions. A "focal point" ${ }^{\$ 5}$ solution has characteristics that distinguish it qualitatively from surrounding alternatives. Unlike the numerical scale, which is too continuous to provide good resting places, qualitative principles are more difficult to compromise, and focal points thus generally depend on qualitative principles. But a commitment to a principle that provides the basis for a numerical calculation which comes out at a specific number may provide the support for a stand at that point.

The outcome of any game can best be characterized by the notion of converging expectations. $^{46}$ A good example is the remarkable frequency with which long negotiations over complicated quantitative formulas or shares in some benefits and costs are ultimately influenced by a seemingly irrelevant previous negotiation. Prece-

\footnotetext{
${ }^{11}$ See $\$$ ro8, 81 Stat. 485 (1967). See Martin \& Symington, supro note 14, at 244-47.

4 See Douglas, The Peaceful Settlement of Industrial and Intergroup Disputes, I J. Confuicr REsolution 69 (I957).

${ }^{13}$ See K. Boulding, supra note 29 , at 311 .

“T. Schelling, supra note 28 , at II4.

${ }^{45}$ Id. at III.

st See id. at II4.
} 
dent seems to exercise an influence that considerably exceeds its logical importance since both parties recognize it as a focal point. Past bargains become precedents for present situations in that they often remove from conscious consideration many agreements, decisions, and commitments that might well be subject to renegotiation as conditions change. ${ }^{47}$

If the outcome of a game is seemingly already determined by the participants' perception of the configuration of the problem itself and where the focal point lies, it would seem that the scope of bargaining skill would be insignificant. But it can be argued that the obvious outcome depends greatly on how the problem is formulated, on what analogies or precedents the definition of the bargaining issue calls to mind, and on the kinds of data that may be available to bring to bear on the question in dispute. Thus bargaining skill in air pollution control can be seen to be important before bargaining actually begins by being able to give prominence to some particular outcomes that would be favorable.

\section{Conclusions on Bargaining Theory}

Several aspects of the many facets of bargaining have been reviewed. These aspects-incrementalism, ritualization, continuing negotiation, and focal point solutions-all suggest that rationality in bargaining outcomes is a function of basically psychic phenomena. At first this view may appear to run contrary to the accepted economic notion that "rationality" is evident only in the minimum-cost solution. But a broader view of decision making may suggest that the least-cost solution is most readily approximated through procedures which take full cognizance of the psychic elements in any bargaining situation and which channel these elements in the direction of a mutually sought, economically sound goal.

\section{V}

\section{The ON-Site Incineration EXaMple}

An example of decision making in air quality management that helps to illustrate the discussion of bargaining is the attempt to reduce particulate emissions in New York City. During the mid Ig6os the heightening concern of the public in New York City with air pollution was focused on visible suspended particulates. During this time, more than ninety per cent of the 50,000 complaints received per year by the Department of Air Pollution Control were related to visible emissions. Public attention was particularly focused on the approximately I2,000 apartment house and commercial incinerators which emitted an estimated 8,400 to 9,000 tons of particulates per year into the atmosphere. These incinerators became the first important issue in air quality management to face the city administration.

In 1966, responding to public pressure, the City Council passed, in some haste,

\footnotetext{
${ }^{27}$ See R. CyerT \& J. MARCF, supra note 35 , at 33.
} 
a local law dealing with the reduction of sulfur dioxide emissions from fuel burning, the use of bituminous coal, the upgrading of municipal incinerators, the upgrading of existing private on-site incinerators, and the banning of incineration in new buildings. Of particular interest is the section of the law prohibiting construction of residential and commercial on-site incinerators after May 1968 and requiring the upgrading of all existing ones. ${ }^{48}$ The first deadline under the law was May 20, 1967, a year after its passage. At that time the owners of an unknown number of incinerators in buildings of seven or more stories were to have completed construction of unspecified control equipment to meet criteria for levels of emissions which had at that time not yet been defined. Local Law I4, as it was called, also had a May 20, 1968, deadline for the upgrading of buildings under seven stories. The law states that the process of upgrading includes the "installation and use of an auxiliary gas burner regulated by automatic firing clocks, an overfire air fan and nozzle system and control apparatus as may be defined by the [Commissioner of Air Pollution Control]." ${ }^{49}$ Basically the required procedure involved the installation of a firebox that burns the refuse efficiently and a scrubber system-a motor-driven device to force the smoke through a special water bath that will remove the heavy particulates. Only compactors would be permitted in new multiple dwellings. This fairly direct attempt at controlling particulate emissions, although not an ideal approach, might seem to some people a useful first step in the direction of cleaner air. Unfortunately it was not.

Why was this the case? The initial problem was that the Department of Air Pollution Control had relatively little time to develop specific criteria for upgrading as required under the law. As a result, the criteria were not formally adopted by the Board of Air Pollution Control until five months before the actual upgrading of the first group of apartment houses was to have been completed. A second problem was that the Department of Air Pollution Control had no enforcement powers to require compliance before the May 20, 1967, deadline. The options were to seal every noncomplying incinerator on or after that date or expedite compliance later. The first deadline came and passed with few completed upgradings. At one time about sixty incinerators were under seal by the Department. This state of affairs was partially due to questions that were raised as to who would not be required to upgrade their equipment. In an interpretation of Local Law i4 the City Corporation Counsel ruled that the law permitted every incinerator which had been installed before on-site incinerators became mandatory in $195 \mathrm{I}$ to be closed down voluntarily rather than upgraded. Then, in August 1967 , the Corporation Counsel interpreted the absence of any incinerator provision in the new city housing maintenance code to mean that almost all existing incinerators were now "volun-

\footnotetext{
${ }^{48}$ Local Law 14, May 20, I966, N.Y. City AdMIN. Code \$\$ 892-2.0 to 897-2.0 (Supp. 1967-1968).

${ }^{40}$ N.Y. CitY AdMiN. Code § 892-4.3 (Supp. 1967-1968).
} 
tary" and could close down rather than upgrade, which meant that the owner might convert to refuse chutes and handle raw or compacted refuse.

An additional complication was a virtual moratorium that was declared on public statements on the issue by the city administration on the ground that the Commissioner of Air Pollution Control was being sued by the New York Real Estate Board and some private real estate interests for imposing a law that was deemed to be "arbitrary and capricious." Another factor was that the Department of Sanitation was not prepared to collect an unknown amount of refuse that formerly was burned. Although there were other reasons why the Sanitation Department could not be counted on to collect the refuse, the Department cannot be blamed for viewing with alarm the prospect of picking up some unspecified amount of refuse that was previously burned in on-site incinerators.

As a result of these developments the city administration finally decided that the law in its original form was unworkable. On the basis of the experience gained, the law was amended in two ways that are more in agreement with the minimum cost approach and bargaining theory. These amendments related to the generation of alternatives to upgrading and the timing of compliance dates.

Before the amendments were introduced, a cost study of the alternative ways of approaching the problem of reducing particulate emissions from on-site incincrators was carried out. ${ }^{50}$ The study considered the varying size of buildings, operating expenses, labor costs, capital investment, and the distribution of unit costs among a number of apartments. The results of this research indicated that the larger buildings would find it most economical to upgrade and that middle-sized buildings could be left to decide for themselves whether it would be cheaper to compact or to upgrade. It was predicted that only buildings which had about fifty units or less per incinerator would find it more economical to shut down. Using these data, the Department of Air Pollution Control estimated the refuse output from the projected shutdowns and determined that the Department of Sanitation could handle the additional volume over a three-year period. Although the actual amendment to the law as passed by the City Council did not include giving the option to every landlord to choose the method which he considered to be the cheapest, the option to shut down for buildings with forty or fewer dwelling units per incinerator was passed as a direct result of the economic analysis.

Another amendment provided a deadline for submission of compliance plans six months prior to the completion deadline. Various strategies of noncompliance that were so successful under the original law have a much lower probability of success now that the Department of Air Pollution Control can use an incremental approach to pollution abatement, which will avoid unexpected reactions and smooth

\footnotetext{
${ }^{50}$ Task Force 2 of the Comm. for Implementing Local Law 14, Economics of Upgrading or Discontinuing Incineration (mimeo., Oct. 3, 1967).
} 
out the "lumpy" features of compliance programs. In keeping with bargaining theory, the "game" is spread out over a longer period of time.

The on-site incinerator example did not, of course, involve bargaining except in a very general sense, since the behavior that was observed involved noncompliance on the one hand and frustrated attempts at enforcing an unrealistic ordinance on the other. The example does, however, clearly convey both the relevance of decision theory to explain the way decisions are made and the importance of comprehending the least-cost principle in a program of direct regulation. Some further reflection on the role of bargaining as it is apt to evolve in air pollution control programs and other environmental management programs should suggest that the least-cost solution can and should be sought in a regulatory program, both by explicit recognition of the cost-benefit nexus and by giving bargaining a chance to function in conjunction with market forces. Indeed, it is possible to assert that regulation strategically employing cost-benefit analysis and market forces can yield solutions to particular pollution control problems that the regulators themselves are not wise enough to devise.

\section{VI}

Devising a Hypothetical Regulatory Scheme:

\section{Bargaining and the Least-Cost Solution}

\section{A. The Shape of Regulatory Programs, Present and Future}

New York City's amended incinerator rules represent an across-the-board legislative attempt to control gross pollution from a very common type of emitter. While bargaining theory explains in some measure the experience with the original attempt and the evolution of the amendments, no opportunity for individual bargaining was actually observed. However, control of other types of pollution will almost necessarily involve ad hoc regulation of individual industrial polluters who cannot appropriately be dealt with by general legislation or rule-making. ${ }^{51}$ In these circumstances face-to-face bargaining will be almost essential as a means of dealing with individual polluters.

As local air pollution control ordinances and statutes are now formulated, bargaining does not have a clear chance to operate, though practice almost inevitably opens some opportunities for give and take between polluters and the control agency in both the standard setting and compliance stages. Most of the legislation, which appears to have been modeled after zoning legislation, either establishes fixed emission standards or delegates the setting of the contemplated standards to the control

\footnotetext{
${ }^{\mathbf{1}}$ Holden notes the inadequacies of state water pollution control legislation for this purpose. $M$. Holden, Pollution Control as a Bargaining Process: An Essay on Regulatory Decision-Maxino (1966).
} 
agency. Because fixed standards not only conflict with the least-cost principle but may raise potental constitutional problems, the statutes generally provide for variances to be granted by the agency. A typical variance provision is this one from the Illinois statute:

The Board may grant individual variances beyond the limitations prescribed in this Act, whenever it is found, upon presentation of adequate proof, that compliance with any provision of this Act, or any rule or regulation, requirement or order of the Board, will result in an arbitrary and unreasonable taking of property or in the practical closing and elimination of any lawful business, occupation or activity, in either case without sufficient corresponding benefit or advantage to the people. ${ }^{52}$

The hardship required to be shown is a considerable one, though much is left to agency and court interpretation. One would have to conclude that, while the typical statutory language appears to permit variances only in extreme cases-perhaps only in those having constitutional dimensions ${ }^{53}$-an agency might, by seizing on the requirement that there be a "corresponding benefit or advantage," indulge in as much comparison of benefits and costs as it might wish. On balance, however, existing legislation appears to give less than sufficient sanction to methods of finding least-cost solutions.

The Air Quality Act of 1967 provides that states shall give effect to federally determined air quality criteria and control techniques once they are promulgated by HEW, which is also granted power to review the standards established and the proposed plan of enforcement. 54 It was apparently contemplated by Congress that new state and local legislation would be forthcoming, and this expectation, coupled with a fairly clear congressional mandate that pollution control be undertaken selectively in light of technological and economic feasibility, ${ }^{55}$ suggests that new thought should be given to devising machinery that will be capable of doing this job most effectively. Indeed, if the concepts of "technological and economic feasibility" are equated with cost-benefit analysis, the question arises whether many existing regulatory schemes might fail to meet the approval of HEW. The issue that is raised is whether the federal act would justify HEW disapproval of state

\footnotetext{
"III. Rev. StAT. ch. III $1 / 2,5240.1$ I (I967).

sa The reference to the constitutional problem simply refers to the general principle that the state cannot curtail one's use of his property without paying "just compensation." The concept of "taking," which appears in the statute, is a constitutional concept which defines whether or not compensation must be paid, and it is applied rather inconsistently. Still, it is possible that curtailment of the property owner's rights to pollute may be classified as a "taking" unless a strong case can be made based on regulation for public health and use of the police power. When aesthetic and generalized environmental quality goals are emphasized, constitutional doubts are increased. See Pollack, Legal Boundaries of Air Pollution Control-State and Local Legislative Purpose and Techniques, in this symposium, p. 33I; see also Michelman, Property, Utility, and Fairness: Comments on the Ethical Foundations of "Just Compensation" Law, 80 Harv. L. Rev. II65 (I967).

st $\$ \$ 107(c), 108(c)(r), 8 \mathrm{r}$ Stat. 485 . See Martin \& Symington, supra note 14 , at 259.

tos The Air Quality Act of $1967, \S \mathrm{IO} 7(\mathrm{c}), 8 \mathrm{r}$ Stat. 485 , provides, "Such recommendations shall include such data as are available on the latest available technology and economic feasibility of alternative methods of prevention and control of air contamination including cost-effectiveness analyses."
} 
and local legislation on the ground of heavyhandedness, or lack of willingness to discriminate among polluters on the basis of the many economic and administrative factors that are comprised in an optimal, least-cost solution. The act suggests that review is limited to assuring only that maximum effectiveness is achieved, ${ }^{56}$ and HEW may be motivated to review only for weakness and not for potential economic hardship on polluters.

The remainder of this article, drawing on these speculations, sets forth some ideas about the shape and function of air quality management programs that can best approximate least-cost solutions. As noted earlier, the outlook is for programs of direct regulation rather than for the sort of effluent fee approach advocated by the welfare economist. While the data shortages that prevent implementation of effuent fees will also plague programs of direct regulation, the latter approach is more familiar and, as noted earlier, can probably sustain a greater amount of regulation in relative ignorance than could a more novel system. But in keeping with the "new federalism," which is often praised as lending itself to experimentation and innovation in ways of attacking particular problems, HEW should not, in exercising its supervisory powers, restrict states to traditional patterns of regulation. Indeed, the regional approach to regulation specified by the Air Quality Act would seem to anticipate and encourage new departures. Such innovation and experimentation at the regional level might produce significantly improved regulatory procedures. ${ }^{57}$

\section{B. Structuring a Regulatory Program to Facilitate Bargaining}

The regulatory setup we conceive of in the following discussion is the one most common in other systems of direct economic regulation. It features an independent regulatory body (the "commission") supported by a staff of legal and technical experts. Membership on the commission is for a relatively long fixed term, and, because of the nature of the issues to be encountered, the members might be required to have expertise of specified types. Thus, a three-member commission might comprise a lawyer, an economist, and a pollution control engineer. The commission

\footnotetext{
${ }^{00}$ The state control plan will be approved if the Secretary finds, among other things, "that such State standards are consistent with the air quality criteria and secommended control techniques issued pursuant to section ro7." $\$$ ro8(c)(I), 8I Stat. 485. (Emphasis added.) Section ro7(c) provides that control techniques should be based on technological and economic feasibility. See note 55 stpra. But the state enforcement plan need only be "consistent with the purposes of the Act insofar as it assures achieving such standards of air quality within a reasonable time," and must provide "a means of enforcement by State action, including authority comparable to" certain emergency powers provided in the act. $\$ 08(\mathrm{c})(\mathrm{x})$, 8I Stat. 485 . Thus the emphasis arguably is on achieving prompt compliance and not on cost effectiveness.

${ }^{87}$ One possible, perhaps even a likely, evolution from the present system would require polluters to pay for the variances they seek, the fee to be set in accordance with damage estimates. If variances were purchased rather than granted, the system would change profoundly, with variances becoming more palatable to the public and the control agency. Bargaining over the fees would yicld some of the benefits sought in the program hypothesized below.
} 
would operate as an independent decision maker, and its final rulings would be subject to judicial review. The agency staff bears the major enforcement burden and provides the evidence and expertise which guides the commission's efforts.

Any attempt to hypothesize about the outlines of an enforcement program that attempts to approach a least-cost solution through administrative means must recognize the desirability of avoiding the use of litigation before either judicial or administrative tribunals as the primary means of achieving abatement in individual cases. The limitations of both legal and technical staff resources, the importance of achieving prompt relief, the difficulty of resolving difficult and highly uncertain technical issues in an adversary proceeding, and the considerable administrative costs involved, all point to the need for minimizing the use of litigation whenever possible. ${ }^{58}$ The approach that would be most helpful in achieving this objective would be to structure regulation to encourage the use of bargaining and settlements as the primary means of accomplishing regulatory objectives. Such a structuring would most likely include the following conditions:

(r) The control agency's regulations should provide for establishment of formal communication with both actual and potential polluters. Thus it might be required that all polluters within the agency's jurisdiction file reports with the agency on their present emission levels and perhaps a ten-year estimate of anticipated increases or decreases in these emissions. Other continuing contact would also be desirable, and informal conferences could be called that would bring the agency staff, trade associations, and other interest groups together to discuss the local problems. The author's interviews with Los Angeles Air Pollution Control District personnel confirm that informal conferences have been a key element in successfully controlling stationary sources of pollution.

(2) The agency's potential sanctions must be substantial but flexible enough so that they could be adjusted to the nature and magnitude of each particular problem confronted. Massive fines for emitting a small amount of pollution, for example, would be a poor agency strategy since it would distort the credibility of the agency's image as an arbiter of the public interest.

(3) The sanctions must put no premium on delay. Thus, a retroactive effluent charge, perhaps accumulating from the date of the agency's complaint, might be provided as a means of compelling a polluter to engage in bargaining in good faith. Filing of a complaint would thus constitute in itself a significant sanction and would most likely lead to bargaining before a formal proceeding was initiated, much as the Federal Power Commission and the Federal Communications Commission have tended to bargain for rate reductions without starting a formal rate

\footnotetext{
88 The inadequacies of a litigation-oriented approach are detailed in NAT'L Resenrch Councit, NAT'L Acadeary of Sciences, Waste Management and Control 203-22I (Pub. No. I400, 1966).
} 
case. ${ }^{59}$ With this strategy, bargaining would also be encouraged after a complaint was filed.

(4) Paradoxically, although the agency's sanctions must be strong enough to encourage polluters to bargain in good faith, they should probably not be so strong as to allow the agency to enforce its will without some recourse to bargaining. This surprising condition-that weaker sanctions may be desirable-is dictated by the conclusion of studies of mixed conflict and cooperation situations that the "game" will not be constituted in good faith unless each side has something to win and something to lose, and that both must be in a position to lose if an outcome is not achieved. The final sanction of formal proceedings can and should be costly to both the agency and the polluter. Both this and the previous condition reflect the fact that inequality or imbalance in the strength of each party's sanctions will bias the outcomes of bargaining. The proper balance may be difficult to achieve but must be sought if something approximating the optimal, least-cost solution is to be arrived at.

(5) If informed bargaining is to operate to the public's advantage, the agency must be adequately staffed so that it is known that its sanctions will not go uninvoked if agreement is not reached or if bargaining is not conducted in good faith. The abatement of ninety per cent of the emissions from stationary sources of air pollution in Los Angeles County, for example, was achieved in part through the efforts of several hundred Air Pollution Control District employees. The New York experience recited above also illustrates the importance of credibility of sanctions.

(6) Public utility regulation points to the fact that the public's representatives at the bargaining table must be neither altogether free of nor unduly subject to political influence, in order, first, that excessive zeal or laxness can be checked and, second, that polluters may not accomplish through influence what they are unable to achieve by negotiation. Judging with respect to this one point, one might argue that the regulatory framework has been more effective in Los Angeles County than in New York City. California legislation authorizes any county to set up its Air Pollution Control District by resolution of the County Board of Supervisors declaring the need for the District to function. The districts are granted the power to "make and enforce all needful orders, rules, and regulations," ${ }^{100}$ and Los Angeles County was given considerable latitude in attacking its local problems. New York City, like Los Angeles County, has the power to adopt and enforce rules and regulations and authority to require permits and control devices on pollution-generating equipment, ${ }^{\mathbf{B 1}}$ but experi-

${ }^{80}$ See generally Welch, Constant Surveillance: A Modern Regulatory Tool, 8 VILL. L. REv. 340 (1963). See also note 65 infra.

${ }^{\circ 0} \mathrm{Cal}$. Henlth \& Safety Code $\$ \$ 24260$ (West I967).

o1 N.Y. City Adnin. Code $\$ \S 894-2.0,892-3.0,892-5.0$ (1966); Cal. Hearth \& Safety Code $\$ \S 2426 \mathrm{r}-63$ (West I967). 
ence to date as was revealed by the on-site incinerator study, has been that the City Council has actively intervened in the Department's regulatory program. A comparative study of the two agencies shows that Los Angeles Air Pollution Control District has had much more freedom in the development of rules and regulations. ${ }^{62}$

(7) Experience with other types of regulation also suggests the desirability of maintaining public control of administrative discretion through openness in decision making. Thus, the data submitted by both the polluter and the agency staff, the terms of the settlement itself, the staff's reasons for accepting it, and the commission's approval should be on public file. ${ }^{63}$ Also useful might be annual or more frequent reports of settlements, together with underlying data, which could be used by the legislative body to which the agency is responsible. ${ }^{61}$

(8) A final precondition for effective bargaining is a clearly defined legal framework within which bargaining can operate. This is essential so that the bargainersthe agency staff and the individual polluter-can largely avoid differences on questions of legal principle while concentrating on the development of the technical and economic data needed to reach a judgment about potential least-cost solutions. ${ }^{65}$ Included among the many issues that ideally need to be resolved and eliminated from dealings with individual polluters are as many of the overriding facts as possible about the air pollution problem in the particular airshed. Such questions as estimates of pollution damage in general and attribution of this damage to particular pollutants would be best resolved authoritatively after public hearings open to all interested parties. Bargaining with individual polluters could then proceed without calling these matters back into question. Further discussion below considers how certain specific issues are better resolved in general agency rule-making proceedings than in case-bycase bargaining or adversary proceedings.

If conditions such as the foregoing could be created, face-to-face bargaining could be made to serve an important function in the administration of an effective air pollution control program. It is argued that the advantages would be many, including the establishment of cooperative attitudes between regulators and industry, which would encourage a joint search for solutions to problems; a de-emphasis of

\footnotetext{
as Hagevik, Decision Processes in Air Quality Management (unpublished dissertation, forthcoming in I969).

${ }^{\circ 8}$ The Air Quality Act of $1967, \S 108(c)(5), 81$ Stat. 485 , states that in connection with hearings conducted under the act, "no witness or any other person shall be required to divulge trade secrets or secret processes." Some confidentiality must be provided by any regulatory scheme.

of Evaluation of agency performance by the legislature is one of the more important aspects of a rational decision process. See A. Manss \& M. Hufschmidt, Design of Water Resource Systexs ch. I5 (1962).

${ }^{\circ 5}$ Testimony to the importance of establishing such a framework appears in an opinion of the FCC defending the decision to commence the first full-scale rate case against AT\&T. In response to Bell's stated preference for bargaining as a rate-making method, the Commission stated, "Indeed, we believe that the standards and criteria developed on the record here will enable us to employ continuing surveillance [i.e., bargaining] even more effectively in the future." Re American Tel. \& Tel. Co., 6r P.U.R.3d 554, 559-60 (1965). The words "even more" are self-serving.
} 
fact finding through quasi-judicial processes and the avoidance of "swearing contests," which are characteristic of adversary proceedings requiring expert testimony; speed, flexibility, and efficiency in the sense that appellate proceedings and timeconsuming judicial review would be avoided; and a more efficient use of technical, administrative, and legal staffs.

\section{Toward a Least-Cost Solution}

There is an axiom among engineers that one can "go slow by running too fast." Although this statement can be interpreted by control officials with some justification as a polluter's excuse for doing nothing, the establishment of the preconditions for an effective control program is a case where the axiom applies. The structuring of the process that will produce efficient resource allocation depends in large part, as we have noted, on the decisions of the legislators who create the sanctions and provide the enforcement staff and on the establishment of a clear legal and factual framework within which to operate. Since a prime objective is to keep as many issues as possible out of litigation, the agency needs the authority to negotiate concerning factual uncertainty. Given the state of the art in environmental management, the legislators need to realize that the "best guess" approach requires that some substantial degree of discretion be given to the agency and its technical staff.

The commission will begin developing the necessary legal and factual framework by holding public hearings as a prelude to authoritative findings on these factual issues:

(I) the total damages attributable to air pollution in the airshed.

(2) the allocation of these damages to each pollutant or each major group of sources. The findings on these first two points need not be sufficiently detailed to satisfy a welfare economist, and it is obvious that the goal is simply the best estimates possible.

(3) an inventory of emissions, including the total amount of each pollutant emitted at particular times and in particular areas.

(4) the relationship of emission levels to the assimilative capacity of the ambient air. This would be determined by using a relatively simple atmospheric diffusion model and air quality monitoring devices. Thus, New York City is now putting into operation an aerometric system of monitoring stations which record and transmit data on levels of sulfur dioxide, dustfall, suspended particulates, and smoke shade on a continuous basis to the Department of Air Pollution Control; New York has also developed a simple model which fairly accurately describes the complex diffusion of pollutants in the city.

(5) the objectives of the abatement program, stated in terms of air quality and the level of damages anticipated as optimal for the airshed as a whole. ${ }^{06 \mathrm{z}}$

\footnotetext{
${ }^{\text {ork }}$ See note 70 infra on the derivation of such objectives.
} 
Some of the foregoing factual judgments would be based in part on the air quality criteria to be issued by HEW under the Air Quality Act. ${ }^{66}$ Additional evidence would be required, and the agency's conclusions should be buttressed by subsidiary findings and a reasoned opinion. All such findings would be subject to periodic review and revision, each time following the procedures employed in the initial formulation. Taken all together, these findings should give a sufficiently clear picture to allow our decision-making and bargaining framework to begin functioning.

An additional matter that the agency would probably find it appropriate to resolve in a rule-making proceeding is the development of a generalized technique for determining a polluter's contribution to the region's over-all concentration of pollutants. Once this issue was settled in principle, the questions at issue with each polluter would be (I) his respective contribution of pollutants to concentrations in the ambient air, which would probably be fairly close to the proportion of total emissions for which he was responsible, adjusted for such factors as wind, timing of emissions, and stack height; and (2) the polluter's costs associated with varying levels of abatement.

Ideally the agency staff would be able to negotiate effectively within this framework of settled legal and economic principles and authoritative general findings of fact concerning the extent and danger of pollution. The issues at stake in the bargaining with individual polluters would be almost exclusively factual and would be susceptible to quantified solutions, thus facilitating some compromise in areas of valid doubt. Focal point bottlenecks could be largely avoided since matters of legal and economic principle would have been eliminated for the most part by rule making; where legal questions did arise they could be set aside for separate authoritative decision by the commission. Such procedures would allow time for incrementalism to operate to narrow gradually the range of possible results, and the continuing negotiating machinery, which would be focused primarily on technical issues, would provide a hospitable climate for the resolution of these issues. ${ }^{67}$

The strategy of a least-cost solution within a bargaining framework suggests that the legislative body to which the control agency is responsible must clean its own house first by upgrading or abandoning any municipal incinerators it operates and reducing the emission levels from governmental heating and generating plants. This is necessary to avoid the embarrassing-and legitimate-charge that a governmental jurisdiction is forcing the private sector to clean up its pollution while con. tinuing to pollute the air itself. This has been a continuing accusation in New York

\footnotetext{
${ }^{60} \oint_{107}, 8 x$ Stat. 485 ( 1967 ). But see note 70 infra on the theoretical deficiencies of the HEW criteria.

${ }^{\text {or }}$ One of the reasons given for the success of the Los Angeles Air Pollution Control District is that there has been a great deal of cooperation between the technical staff of the District and the technical staffs of the regulated industries.
} 
City where the municipal incinerators had not been upgraded by the time private on-site incinerators were to be upgraded.

The agency's next move world be to tackle the sources of air pollution which can have their levels of pollutant emissions reduced in fairly straightforward ways that clearly yield greater benefits than costs. This might mean that the agency should proceed against those polluters who are perceived by both the control agency and the public at large as the most significant polluters of the atmosphere in the jurisdiction, but not always. For example, it is now recognized in New York City that the formulators of Local Law 14 made a strategic error in the structuring of the legislation by requiring that initial action be taken against on-site incinerators even though they were a source of easily visible localized particulate concentrations.

Initial agency action, in addition to avoiding potential charges of being "arbitrary and capricious," must consider the impact of highly localized costs in relation to diffuse benefits and whether the technological and administrative solutions to problems are at hand. In the New York case, it can clearly be argued that a much greater reduction of air pollution could have been achieved at a lower cost to individual polluters by proceeding initially against the emissions of sulfur oxides and particulates resulting from the burning of fuel oil. A technical solution-switching to low-sulfur fuel oil-was available which could be implemented without too much difficulty. ${ }^{68}$ In fact, due to difficulties involved in getting thousands of on-site incinerators upgraded or shut down, the program to change to a low-sulfur fuel, which was initiated after the incinerator upgrading, yielded tangible benefits much sooner.

Selecting the initial target in this manner has considerable implications in terms of later control efforts. A demonstrated success gives the agency a good image, reflects positively on the elected officials who give the agency support, and lessens the opposition of businessmen to control efforts aimed at them. The stage is also set for conflict resolution procedures such as negotiation and bargaining rather than for the polarization of attitudes that results in litigation.

One of the more important matters that should concern a control agency operating under our system is the establishment of a method of determining the maximum abatement expenditure - or level of abatement-that could be required of an individual polluter. This complex question has practical importance because all polluters cannot be attacked at once and the marginal unit abatement costs apparently justified when pollution levels are high will seem inappropriate when more nearly tolerable concentrations have been achieved. ${ }^{60}$ All polluters should be subject to the

\footnotetext{
${ }^{68}$ Although making the use of low-sulfur fuel mandatory is in conflict with the economists' rational model, it can still be viewed as a sound decision in keeping with our strategy, which would allow mixing of necessary approaches. At a later stage another approach should probably be substituted.

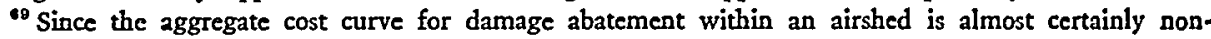
linear-costs increase as the more obvious sources of pollution are controlled and as the more serious damage is eliminated-an estimate of the amount of damage reduction obtainable from a unit of abate-
} 
same maximum, however, and the derivation of this maximum is extraordinarily difficult. A very rough figure can be derived, however, if air quality standards or goals-indicators of the level of air quality desired within a given jurisdictionhave been developed from objectives and constraints specified in the legislative process and in HEW's air quality criteria. Beginning with these goals, which will necessarily include estimates of the abatement outlays required to achieve them, ${ }^{70}$ the agency can arrive at a general estimate of the theoretical emission level at which all marginal expenditures would equal marginal benefits. No polluter should be required to abate below that emission level which he would be permitted to maintain under such optimal conditions, or, in other words, to pay more for a unit of abatement than would yield a net gain if optimal conditions prevailed.

\section{Conclusion}

Optimizing methods are a guide to decisions, not a philosopher's stone that substitutes for decision. With a view to achieving practical results, it has been pointed out how bargaining might contribute to finding a least-cost solution. Although bargaining is often viewed as a distributional device rather than one that promotes efficiency, it has been shown that the latter view can also be taken. Having been directed, or having found it expedient, to adopt a cost-benefit approach, the control agency would be responsive within our framework to polluters' arguments based on a comparison of marginal benefits and costs associated with alternative emission reduction techniques. The polluter would most likely be inclined to hold out for the lowest-cost remedy and to develop and advance in the negotiations alternative ways of accomplishing the objectives being sought-an advantage, it will be recalled, usually associated exclusively with effluent fees as a control mechanism. Market forces will thus aid the controllers in seeking the most efficient approach to pollution damage reduction. For these reasons the outcome of a properly structured bargaining process should not deviate too far from economic rationality.

The hypothetical regulatory program we have outlined probably represents an ideal difficult to achieve in our society today. Why it may be so is a matter for

ment by the first polluter proceeded against might be high if this polluter was considered as an isolated source. This would apparently justify imposition of equally high abatement costs. Such a view of marginal control expenditures and benefits is deceptive, however, in that if other firms or groups of firms were forced to abate sequentially, their positions on the curve would be lower and their expenditures would yield a lower return, thereby decreasing the amount of required investment. Thus, a simplistic comparison of marginal costs and benefits is not enough, since this would result in applying a different standard to each polluter depending on the sequence in which they are attacked.

${ }^{70}$ See Thomas, The Animal Farm, A Mathematical Model for the Discussion of Social Standards for Control of the Environment, 77 Q. J. EcoN. 143 ( 1963 ). Thomas points out that to set a quality criterion is to impute a cost-benefit ratio. Id. at 147 . Thus the starting point for pollution abatement programs should be cost-benefit analysis and not arbitrarily determined quality criteria or emission standards. But see H.R. REP. No. 728, goth Cong., Ist Sess. I6 (1967), which states that economic considerations are to have no place in the development of HEW's criteria. 
conjecture and concern, and the most pessimistic conclusions one might draw is that the law and the legal system are in many respects incompatible with the scientific pursuit of optimal conditions under constraints of uncertainty. ${ }^{71}$ We have proposed a scientific approach to pollution control requiring gross estimates of pollution damage and abatement costs. A problem of concern in this framework is the difficulty of making damage and cost estimates having enough objective validity to withstand legal attack when viewed as the product of a hearing record which must contain "substantial evidence" to support the result reached. In many respects informed guesses will be all that the control commission can show, and honesty should compel the commission to admit the depth of human ignorance on the questions in issue and to acknowledge frankly that its findings are made for the purpose of getting on with the abatement job. Courts would then be faced clearly with the problem of allowing regulation to proceed in the dim light of partial knowledge or to cease until science can provide light enough to satisfy the judicial sense of what due process requires.

Experience with the regulatory process in general suggests, however, that agencies do not as a rule confess ignorance but rather pretend to omniscience. While often not disclosing the true basis for their decisions and allowing their opinions to be written in "judge proof" boilerplate by their legal staffs, the agencies assume an air of knowledgeability that belies more than it reveals. This attitude might work in air pollution control as well, and the temptation to adopt it will be great. Control commissions may prefer to fill their opinions with statistics and data and to conclude by solemnly declaring, "Having considered all of the evidence and the relevant legal principles ...." The results may be unimpeachable for the simple reason that the underlying principles relating such items as costs to benefits are not stated and thus not subject to review. The alternative may be unattractive in administrative circles because the necessary estimates are of such precariousness that they can be defended only by candor about the depth of the problem and by apparent conscientiousness in approaching it. Nevertheless, the courts should learn to insist on full disclosure in lieu of obfuscation. Once this is obtained, judicial review should then require only the exercise of the agency's expert judgment on the best information and data available, incomplete and unsatisfying as it may seem. In no event should the courts prevent effective regulatory action solely because science has not yet yielded the secrets needed to realize the the regulatory ideal.

\footnotetext{
${ }^{71}$ For a more optimistic view, see National Research Council, supra note 58, at 204, 207-09, $214-17$.
} 